\title{
Clinical and pharmacogenetic determinants for the discontinuation of non-ergoline dopamine agonists in Parkinson's disease
}

\author{
Maurits E. L. Arbouw • Kris L. L. Movig • Toine C. G. Egberts • Petra J. E. Poels • \\ Jeroen P. P. van Vugt • Judith A. M. Wessels • R. J. H. M. van der Straaten • \\ Cees Neef • Henk-Jan Guchelaar
}

Received: 18 February 2009 / Accepted: 19 July 2009 / Published online: 8 August 2009

(C) The Author(s) 2009. This article is published with open access at Springerlink.com

\begin{abstract}
Objective To identify determinants for the discontinuation of non-ergoline dopamine agonist (DA) treatment in patients with Parkinson's disease (PD) and to identify genetic determinants in genes encoding dopamine receptor (DR)D2 and DRD3 in a exploratory analysis.
\end{abstract}

\footnotetext{
M. E. L. Arbouw • T. C. G. Egberts

Department of Clinical Pharmacy, University Medical Center Utrecht, Utrecht, The Netherlands
}

\section{E. L. Arbouw • T. C. G. Egberts}

Division of Pharmacoepidemiology and Pharmacotherapy,

Utrecht Institute for Pharmaceutical Sciences,

Faculty of Science, Utrecht University,

Utrecht, The Netherlands

M. E. L. Arbouw $\cdot$ K. L. L. Movig

Department of Clinical Pharmacy, Medisch Spectrum Twente,

Enschede, The Netherlands

\section{P. J. E. Poels}

Department of Neurology,

Radboud University Nijmegen Medical Centre,

Nijmegen, The Netherlands

\section{J. P. P. van Vugt}

Department of Neurology, Medisch Spectrum Twente,

Enschede, The Netherlands

C. Neef

Department of Clinical Pharmacy and Toxicology,

University Hospital Maastricht,

Maastricht, The Netherlands

J. A. M. Wessels • R. J. H. M. van der Straaten

H.-J. Guchelaar $(\square)$

Department of Clinical Pharmacy and Toxicology,

Leiden University Medical Center,

P.O. Box 9600, 2300 RC Leiden, The Netherlands

e-mail: h.j.guchelaar@lumc.nl
Methods Patients included were first-time users of the nonergoline DA ropinirole or pramipexole who had been diagnosed with PD before 2005. Treatment discontinuation was defined as a gap of 180 days or more between two refills of the DA. Non-genetic determinants for discontinuation were studied in the overall population, and genetic determinants [DRD2 141C Ins/Del, DRD2 (CA)n STR, DRD2 TaqIA, DRD3 MscI single nucleotide polymorphism (SNP) and DRD3 MspI SNP] were studied in a subgroup. Cox proportional hazard analysis was used to estimate the hazard ratios (HR) for the discontinuation of non-ergoline DA treatment. Results The study population comprised 90 patients. Apomorphine use was associated with non-ergoline DA discontinuation, although the apomorphine group consisted only of three patients [HR 6.26; 95\% confidence interval (CI) 1.85-21.2]. Daily levodopa dosages between 500 and $1000 \mathrm{mg}$ were positively associated with discontinuation (HR 2.31; 95\% CI 1.08-4.93). Included in the exploratory pharmacogenetic analysis were 38 patients. The absence of a $15 \times$ DRD2 CA repeat allele was significantly related with a decreased discontinuation of non-ergoline treatment (HR 0.23 ; 95\% CI $0.07-0.81$ ). The DRD3 MspI polymorphism showed a non-significant allele dose effect, suggestive of a causal relationship.

Conclusion This study identified apomorphine use and levodopa dosages between 500 and $1000 \mathrm{mg}$ as nongenetic and the $15 \times$ DRD2 CA repeat allele as genetic determinants for the discontinuation of non-ergoline DA treatment in patients with PD. More research is needed to replicate these findings.

Keywords Determinants - Discontinuation ·

Dopamine agonists · Dopamine receptors .

Parkinson's disease $\cdot$ Pharmacogenetics · Pramipexole ·

Ropinirole 


\section{Abbreviations \\ DA Dopamine agonist \\ DR Dopamine receptor \\ PD Parkinson's disease}

\section{Introduction}

Long-term treatment with levodopa, which is still considered to be the gold standard for the pharmacotherapeutic management of patients with Parkinson's disease (PD), often leads to motor complications, such as wearing-off and dyskinesias [1]. As a result, dopaminergic therapy with dopamine agonists (DA) has gained popularity as initial therapy in younger patients and as add-on therapy in older individuals. However, it has been demonstrated that in clinical practice over half of patients initiating non-ergoline DA ropinirole and pramipexole therapy have discontinued (51 and 60\%, respectively) within 3 years [2].

Remarkably, determinants for the discontinuation of non-ergoline DA therapy are largely unknown. We hypothesize that several non-genetic factors, such as the duration of PD or concurrent drug use, are associated with this discontinuation of non-ergoline DA use. We also suggest that genetic polymorphisms in the genes encoding the dopamine receptor (DR) are associated with this discontinuation. Several polymorphisms in the DR have been identified [3-7], and those in DRD2 and DRD3 could be important determinants because the non-ergoline DA have high binding characteristics for the DRD2 subgroup and a preferential affinity for the DRD3 subgroup.

The aim of this study was to identify non-genetic determinants for the discontinuation of non-ergoline DA and to perform an exploratory analysis of genetic determinants in genes encoding DRD2 and DRD3.

\section{Methods}

Setting, study population and data collection

The setting of this cohort study was the neurology department of a large teaching hospital in Enschede, The Netherlands. Outpatients diagnosed with PD before 2005 who had received a non-ergoline DA (ropinirole or pramipexole) for the first time were included. Prescription data were retrieved from community pharmacies after obtaining the patients' informed consent as described in an earlier publication [2]. The date of the first prescription of the DA was defined as the index date. To ascertain firsttime use, we required that the patients had at least 180 days of prescription history for any prescribed drug before the index date. In addition, patients needed to have at least 180 days of prescription data for any medicine after the index date. Thereafter, patients were asked for informed consent in order to obtain saliva for DNA collection and pharmacogenetic analysis. All genotyped patients were of Caucasian ethnicity. The patients included in the genetic analysis were asked in a semi-structured interview by a researcher (MA) if they could recollect any period in which they had discontinued non-ergoline DA treatment and, if so, what was the reason for this discontinuation. The study was approved by the medical ethics committee.

\section{Endpoint}

The endpoint of this study was discontinuation of nonergoline DA treatment. Patients were considered to have discontinued ropinirole or pramipexole treatment when more than 180 days elapsed between two consecutive pharmacy refills of the non-ergoline DA. Patients who persisted with therapy to the end of their observation time were censored on the last day of their follow-up. Consequently, patients who were lost to follow-up (e.g. moved to another place or died) were censored on the last day of their follow-up.

\section{Determinants}

Non-genetic determinants present at the index date were recorded from the medical charts and extracted from the prescription histories. We investigated gender, age, duration of PD, type of non-ergoline DA treatment, concomitant use of other antiparkinson drugs, daily levodopa dosage, and concomitant use of antipsychotics and antidepressants. The mean dosage of non-ergoline DA during follow-up was also investigated as a determinant for discontinuation.

Genetic determinants for discontinuation of non-ergoline DA treatment were studied in the subgroup of patients who gave separate informed consent for genetic testing. Polymorphisms in the DRD2 gene and DRD3 gene were selected based on indications for clinical relevance determined from previous publications: DRD2 141C Ins/Del

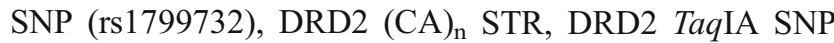
(rs1800497), DRD3 MscI single nucleotide polymorphism (SNP) (rs6280) and DRD3 MspI SNP (rs4646996) [8].

\section{Genotyping}

Saliva specimens were collected with Oragene-DNA tubes (DNA Genotek, Kanata, ONT, Canada). Polymerase chain reaction analyses were performed under standard conditions on the MyCycler system (Bio-Rad, Veenendaal, The Netherlands). The Hotstart PCR Mastermix was obtained from Qiagen (Hilden, Germany). Genotyping was performed according to the protocol provided by the manu- 
facturers (Invitrogen, Breda, The Netherlands; Promega, Leiden, The Netherlands). Allele frequencies were as follows: for DRD2 141-C, 72\% ins, 28\% del; for DRD2 TaqIA (C>T), 71\% C, 29\% T; for DRD2 (CA)n STR, 13\% $13 \mathrm{x}, 11 \% 14 \mathrm{x}, 46 \% 15 \mathrm{x}, 29 \% 16 \mathrm{x}, 1 \% 17 \mathrm{x}$; for DRD3 MscI (Ser $>$ Gly), 79\% Ser, 21\% Gly; for DRD3 MspI $(A>G), 47 \%$ A (absence), 54\% G (presence). The allele frequencies were in accordance with those reported in the literature [8]. The genotype frequencies were in HardyWeinberg equilibrium, and the genotyping success rate was $100.0 \%$. A linkage disequilibrium was found between DRD2 ins/del and the DRD2 TaqIA genotype $\left(r^{2}=0.937\right)$.

Data analysis

Fisher's exact test was used to test differences in dichotomous variables, and Student's $t$-test was used for continuous variables. Cox proportional hazard analysis was used to estimate the hazard ratios (HR) for the discontinuation of non-ergoline DA treatment. Cumulative hazards for discontinuation were plotted against the time of follow-up. In the genetic analyses, alleles were combined because of the relative low numbers in the genetic subgroup.

All analyses were performed using SPSS ver. 12.0 (SPSS, Chicago, IL).

\section{Results}

Description of the cohort

Clinical characteristics of the cohort are described in Table 1. The overall study population consisted of 90 patients who were first-time users of a non-ergoline DA treatment; $50 \%$ were ropinirole starters and 50\% were pramipexole starters. The mean follow-up period was 28.7 months. DNA samples for an exploratory pharmacogenetic analysis were available for 38 patients. The flowchart of inclusion in the genetic analysis subgroup is presented in Fig. 1. Compared to the total cohort, patients for whom DNA was available were younger (63.4 vs. 69.8 years; $p<0.001)$ and had a shorter disease duration (4.4 vs. 7.4 years; $p=0.022$ ).

In the overall population, there was a large range in mean daily DA dosage during follow-up: from 0.17 to 6.64 defined daily dosages (DDD). However, most patients used $<1.5$ DDD (81.1\%).

\section{Discontinuation}

Of the patients in our study who started on non-ergoline DA treatment, 35.6, 51.1 and 55.6\% discontinued this therapy after 1, 3 and 5 years, respectively. Of the patients in the subgroup for pharmacogenetic analysis, 31.6, 47.4 and $52.6 \%$ discontinued non-ergoline DA treatment after 1 , 3 and 5 years, respectively. Treatment discontinuation was confirmed by 18 of the 20 patients in the genetic subgroup. In all cases, discontinuation was initiated by the neurologist and were based on insufficient response (four patients, $22.2 \%$ ) and side effects (nine patients, 50.0\%). Five patients $(27.8 \%)$ could not recall the reason of discontinuation. The side effects that were the basis for discontinuation are summarized in Table 2.

Non-genetic determinants associated with non-ergoline DA discontinuation

The results of the Cox regression analysis are presented in Table 3. All 90 patients were included in this analysis. Apomorphine use was associated with non-ergoline DA discontinuation [HR 6.26; 95\% confidence interval (CI) 1.85-21.2]. However, the apomorphine group consisted only of three patients. The use of levodopa resulted in conflicting data in that its actual use was not associated with discontinuation, but within the levodopa users, dosages between 500 and $1000 \mathrm{mg}$ were positively associated with discontinuation (HR 2.31; 95\% CI 1.084.93). Higher dosages of non-ergoline DA were associated with less treatment discontinuation over time (HR for $\geq 0.75$ 1.50 DDD $0.39 ; 95 \%$ CI $0.20-0.75$; HR for $\geq 1.50$ DDD $0.39 ; 95 \%$ CI $0.17-0.88$ ).

Genetic determinants associated with non-ergoline DA discontinuation

The results of the Cox regression analysis of genetic determinants, carried out on 38 patients, are presented in Table 4 . The absence of a $15 \times$ DRD2 CA repeat allele was related to a decreased discontinuation of non-ergoline DA treatment (HR 0.23; 95\% CI 0.07-0.81). Patients with the DRD3 MspI G allele (presence of $M s p$ I restriction site) had a non-significant twofold higher risk of non-ergoline DA treatment discontinuation (95\% CI 0.61-7.17). The DRD3 MspI polymorphism showed an allele dose effect (increase in risk per $\mathrm{G}$ allele), which is suggestive of a causal relationship with discontinuation (A/A: ref; A/G: HR 1.56; 95\% CI 0.42-5.77; G/G: HR 3.50; 95\% CI 0.91-13.4). No other statistically significant associations between genetic polymorphisms and non-ergoline DA treatment discontinuation were detected.

\section{Discussion}

This study identified non-genetic and genetic determinants for discontinuation of the non-ergoline DA ropinirole and 
Table 1 Baseline characteristics of the study cohort

\begin{tabular}{|c|c|c|c|}
\hline Baseline demographic/clinical characteristics of study population & $\begin{array}{l}\text { Overall population } \\
(n=90)\end{array}$ & $\begin{array}{l}\text { Genetic analysis } \\
\text { subgroup }(n=38)\end{array}$ & $p$ value $^{\mathrm{a}}$ \\
\hline Male gender & $49(54.4)$ & $25(65.8)$ & 0.087 \\
\hline Mean age in years (SD); range & $67.8(8.7) ; 48-91$ & $63.4(6.9) ; 49-78$ & $<0.001$ \\
\hline$<65$ years & $29(32.2)$ & $21(55.3)$ & 0.001 \\
\hline$\geq 65$ years & $61(67.8)$ & $17(44.7)$ & \\
\hline Mean duration of PD in years, (range) & $6.2 ; 0-39.3$ & $4.4 ; 0-16.2$ & 0.022 \\
\hline$<5$ years & $47(52.2)$ & $21(55.3)$ & 0.673 \\
\hline$\geq 5$ years & $43(47.8)$ & $17(44.7)$ & \\
\hline Mean follow-up in months; range & $28.7 ; 0.4-91.0$ & $32.0 ; 0.4-91.0$ & 0.288 \\
\hline \multicolumn{4}{|l|}{ Non-ergoline dopamine agonist treatment } \\
\hline Ropinirole & $42(46.7)$ & $19(50.0)$ & 0.671 \\
\hline Pramipexole & $48(53.3)$ & $19(50.0)$ & \\
\hline \multicolumn{4}{|l|}{ Concomitant use of other antiparkinsonian drugs at index date } \\
\hline Amantadine & $17(18.9)$ & $10(26.3)$ & 0.173 \\
\hline Selegeline & $7(7.8)$ & $2(5.3)$ & 0.694 \\
\hline Apomorphine & $3(3.3)$ & $1(2.6)$ & 0.617 \\
\hline Other dopamine agonist & $1(1.1)$ & $0(0)$ & 1.000 \\
\hline Levodopa & $57(63.3)$ & $19(50.0)$ & 0.029 \\
\hline Mean daily levodopa dosage at index date in milligrams (SD); range & $466(331) ; 100-1804$ & $422(280) ; 149-1302$ & 0.485 \\
\hline$<500 \mathrm{mg}$ & $40(70.2)$ & $14(73.7)$ & 0.906 \\
\hline$\geq 500 \mathrm{mg}-1000 \mathrm{mg}$ & $12(21.1)$ & $4(21.1)$ & \\
\hline$\geq 1000 \mathrm{mg}$ & $5(8.8)$ & $1(5.3)$ & \\
\hline \multicolumn{4}{|l|}{ Concomitant use of other medication at index date } \\
\hline Antipsychotics & $12(13.3)$ & $5(13.2)$ & 1.000 \\
\hline Antidepressants & $6(6.7)$ & $3(7.9)$ & 0.694 \\
\hline Mean daily dopamine agonist dosage in $\mathrm{DDD}^{\mathrm{b}}(\mathrm{SD})$; range & $1.17(1.08) ; 0.17-6.64$ & 1.13 (0.89); 0.18-3.91 & 0.787 \\
\hline$<0.75$ DDD & $41(45.6)$ & $19(50.0)$ & 0.273 \\
\hline$\geq 0.75-1.50 \mathrm{DDD}$ & $32(35.6)$ & $10(26.3)$ & \\
\hline$\geq 1.50 \mathrm{DDD}$ & 17 (18.9) & $9(23.7)$ & \\
\hline
\end{tabular}

Values are given as the number $(n)$, with the percentage in parenthesis, unless stated otherwise

PD, Parkinson's disease; DDD, defined daily dose; SD, standard deviation

${ }^{a} p$ value between patients within genetic analysis subgroup vs. those not within genetic analysis subgroup (not shown). The Fisher's exact test for dichotomous variables and Student's $t$-test for continuous variables were used

${ }^{\mathrm{b}}$ Mean of entire follow-up period. $1 \mathrm{DDD}$ ropinirole $=6.0 \mathrm{mg} ; 1 \mathrm{DDD}$ pramipexole $=2.5 \mathrm{mg}$

pramipexole in PD. Non-genetic determinants that were associated with discontinuation were apomorphine use, levodopa dosage, and the dosage of non-ergoline DA during follow-up. In an exploratory pharmacogenetic analysis, we identified a DRD2 $(\mathrm{CA})_{\mathrm{n}}$ repeat polymorphism that was associated with non-ergoline DA discontinuation.

Apomorphine use was associated with a sixtime higher risk of discontinuation. Apomorphine is a potent DA and is used in patients with severe on-off fluctuations. As other, less potent dopaminergic drugs can be discontinued with the initiation of apomorphine therapy, it is not surprising that apomorphine use is associated with non-ergoline DA treatment discontinuation. More than half of the patients included in this study used levodopa when starting nonergoline DA treatment. One might expect that higher levodopa dosages have a higher risk of dopaminergic side effects, often resulting in the discontinuation of other dopaminergic treatment. This is in line with our findings. The use of levodopa itself was not associated with nonergoline DA discontinuation, but within the levodopa users, dosages between 500 and $1000 \mathrm{mg}$ were positively associated with non-ergoline DA discontinuation. However, as levodopa dosages $>1000 \mathrm{mg}$ were not associated with non-ergoline DA discontinuation, this result may have been an artefact due to the relatively small numbers of patients that used $>1000 \mathrm{mg}$ levodopa per day. 
Fig. 1 Flow-chart of inclusion genetic analysis subgroup

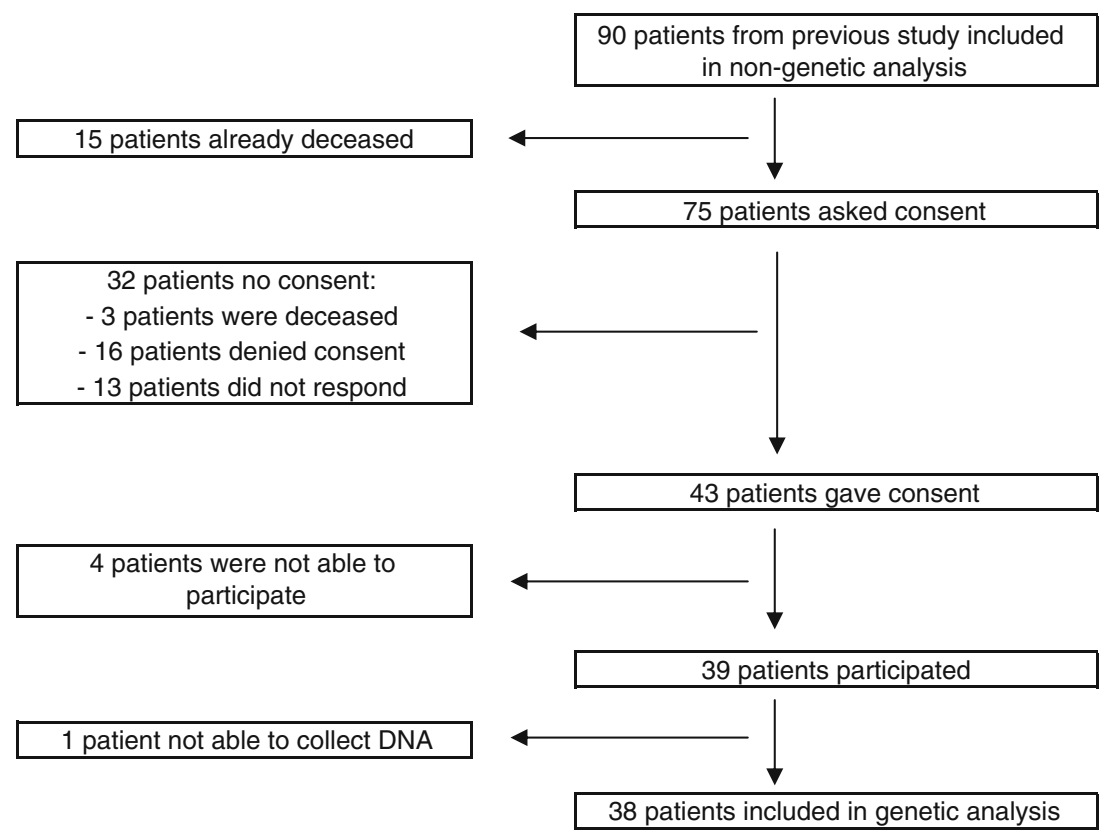

Higher dosages of non-ergoline DA itself were associated with a reduced chance of treatment discontinuation. This can be explained by the fact that the dosage of these drugs is slowly increased in order to minimize adverse events and by the fact that most patients discontinued in the first months after treatment initiation [9]. Thus, this association is a marker for early discontinuation.

We hypothesized that genetic polymorphisms in the genes encoding the DR, specifically in DRD2 and DRD3, could be associated with discontinuation of DA use. Indeed, our data show interesting genetic results. The absence of a $15 \times$ DRD2 CA repeat allele was associated with a decreased risk of non-ergoline DA treatment discontinuation. The DRD2 (CA) n polymorphism is located in a non-coding region of the DRD2 gene, but the precise functional consequence of this polymorphism for the DRD2 protein remains unclear. The DRD3 MspI polymorphism showed an allele dose effect (increase in the risk of treatment discontinuation per $\mathrm{G}$ allele), which is suggestive of a causal relationship. The consequence of this polymorphism on DRD3 functionality remains to be unraveled. The DRD3 MspI polymorphism is located in an intron, suggesting no direct influence of the polymorphism on DRD3 protein function, and is near the MscI polymorphism. However, we found no linkage disequilibrium between these two polymorphisms. It may be that the non-significant association between the DRD3 MspI polymorphism and non-ergoline DA treatment discontinuation is indicative of other polymorphisms not studied in this gene region. Although we expected that the DRD3 MscI Gly polymorphism would lead to increased agonist binding [7, 10], we did not notice an association between this polymorphism and non-ergoline DA discontinuation. Wang and colleagues found that PD patients with the DRD2 TaqIA polymorphism who received levodopa had a higher risk of developing motor fluctuations [11]. Again, we did not find an effect of this polymorphism on DA discontinuation. Our finding may not be surprising as the DRD2

Table 2 Reported reasons for discontinuation of non-ergoline DA treatment in the genetic analysis subgroup

\begin{tabular}{ll}
\hline $\begin{array}{l}\text { Clinical basis for discontinuation of non-ergoline } \\
\text { DA treatment }\end{array}$ & $\begin{array}{l}\text { Genetic analysis } \\
\text { subgroup }(n=38)\end{array}$ \\
\hline $\begin{array}{l}\text { Patients that discontinued non-ergoline } \\
\text { DA treatment }\end{array}$ & $20(52.6)$ \\
Confirmed by patient & $18(90.0)$ \\
Discontinuation initiated by: & $18(100.0)$ \\
Neurologist & \\
Reasons for discontinuation & $4(22.2)$ \\
Lack of sufficient response & $9(50.0)$ \\
Side effects & \\
Excessive daytime sleepiness ${ }^{\mathrm{a}}$ & 3 \\
Hallucinations or psychosis & 2 \\
Nausea & 1 \\
Lightheadedness or dizziness & 1 \\
Hypersexuality & 1 \\
Dopaminergic drug abuse & \\
Diarrhoea & 1 \\
Eczema & 1 \\
Patient can not recall reason & 1 \\
\hline
\end{tabular}

Values are given as the number $(n)$, with the percentage in parenthesis DA, Dopamine agonist

${ }^{\mathrm{a}}$ One patient reported three side effects. 
Table 3 Hazard ratios for discontinuation of non-ergoline DA treatment in overall population

\begin{tabular}{|c|c|}
\hline Demographic/clinical characteristics & $\begin{array}{l}\text { Crude HR, } \\
n=90\end{array}$ \\
\hline \multicolumn{2}{|l|}{ Gender } \\
\hline Male & Reference \\
\hline Female & $0.75(0.43-1.31)$ \\
\hline \multicolumn{2}{|l|}{ Age } \\
\hline$<65$ years & Reference \\
\hline$\geq 65$ years & $1.04(0.57-1.91)$ \\
\hline \multicolumn{2}{|l|}{ Duration of PD } \\
\hline$<5$ years & Reference \\
\hline$\geq 5$ years & $0.81(0.46-1.41)$ \\
\hline \multicolumn{2}{|l|}{ Treatment } \\
\hline Ropinirole & Reference \\
\hline Pramipexole & $1.15(0.66-2.02)$ \\
\hline \multicolumn{2}{|c|}{$\begin{array}{l}\text { Concomitant use of other antiparkinsonian } \\
\text { drugs at index date }(\%)^{\mathrm{a}}\end{array}$} \\
\hline Amantadine & $0.76(0.36-1.62)$ \\
\hline Selegeline & $0.97(0.35-2.71)$ \\
\hline Apomorphine $^{\mathrm{b}}$ & $6.26(1.85-21.2)$ \\
\hline Other dopamine agonist & $0.05(0-702)$ \\
\hline Levodopa & $1.26(0.70-2.28)$ \\
\hline \multicolumn{2}{|l|}{ Daily levodopa dosage at index date } \\
\hline$<500 \mathrm{mg}$ & Reference \\
\hline$\geq 500 \mathrm{mg}-1000 \mathrm{mg}^{\mathrm{b}}$ & $2.31(1.08-4.93)$ \\
\hline$\geq 1000 \mathrm{mg}$ & $1.59(0.47-5.37)$ \\
\hline \multicolumn{2}{|l|}{$\begin{array}{l}\text { Concomitant use of other medication } \\
\text { at index date }(\%)^{\mathrm{a}}\end{array}$} \\
\hline Antipsychotics & $0.62(0.25-1.57)$ \\
\hline Antidepressants & $0.68(0.21-2.18)$ \\
\hline \multicolumn{2}{|l|}{ Daily dopamine agonist dosage ${ }^{c}$} \\
\hline$<0.75$ DDD & Reference \\
\hline$\geq 0.75-1.50 \mathrm{DDD}^{\mathrm{b}}$ & $0.39(0.20-0.75)$ \\
\hline$\geq 1.50 \mathrm{DDD}^{\mathrm{b}}$ & $0.39(0.17-0.88)$ \\
\hline
\end{tabular}

Values are given as the hazard ratio (HR), with the $95 \%$ confidence interval $(\mathrm{CI})$ in parenthesis

${ }^{\text {a }}$ Presence vs. absence (Reference)

${ }^{\mathrm{b}}$ Factors associated with non-ergoline DA discontinuation

${ }^{\mathrm{c}}$ Mean of entire follow-up period: $1 \mathrm{DDD}$ ropinirole $=6.0 \mathrm{mg} ; 1 \mathrm{DDD}$ pramipexole $=2.5 \mathrm{mg}$ (as established by the World Health Organization Collaborating Centre for Drug Statistics Methodology)

TaqIA polymorphism is located in a kinase gene, denoted the ankyrin repeat and kinase domain containing 1 (ANKK1), which is located downstream of the DRD2 gene. It is therefore unlikely that this polymorphism alters DRD2 activity directly.

Several remarks should be made with respect to the methodology used. In this study, use of the non-ergoline DA ropinirole and pramipexole was combined in order to improve statistical power. This can be justified by the fact that both ropinirole and pramipexole are DRD2 agonists with a preferential affinity for the DRD3 subgroup. The choice of the endpoint of this study, discontinuation of nonergoline DA treatment, which encompasses both efficacy and tolerability, is also open to discussion. Since discontinuation related to insufficient efficacy and to intolerability may be mechanistically different, ideally, a stratified analysis on separate endpoints efficacy and tolerability should be performed. However, this could not be done because the reasons for discontinuation in the overall population were not known and because the population in the genetic analysis was too small for subgroup analysis. Moreover, the baseline characteristics in the genetic analysis subgroup differed from those of the overall study population due to the fact that there was a time gap of nearly 2 years between the selection of the overall population and receiving informed consent from patients for the pharmacogenetic analysis. Fortunately, the allele frequencies were in accordance with those reported in the literature [8]. We did not correct for multiple testing as the aim of the genetic subgroup study was to perform an exploratory analysis of genetic determinants. Positive associations should therefore be interpreted with caution. Finally, we included outpatients from only one hospital. Therefore, the results could have been biased by the prescribing patterns of a few clinicians.

Table 4 Hazard ratios for discontinuation of non-ergoline DA treatment in genetic analysis subgroup

\begin{tabular}{|c|c|c|}
\hline Genotype & $\begin{array}{l}\text { Genetic analysis } \\
\text { subgroup }(n=38)^{\mathrm{a}}\end{array}$ & Crude HR $(95 \% \mathrm{CI})$ \\
\hline \multicolumn{3}{|l|}{ DRD2 141-C ins/del } \\
\hline Ins/Ins & $20(52.6)$ & Reference \\
\hline Ins/Del + Del/Del & $18(47.4)$ & $1.00(0.42-2.42)$ \\
\hline \multicolumn{3}{|l|}{ DRD2 Taq1A $(\mathrm{C}>\mathrm{T})$} \\
\hline $\mathrm{C} / \mathrm{C}$ & $19(50.0)$ & Reference \\
\hline $\mathrm{C} / \mathrm{T}+\mathrm{T} / \mathrm{T}$ & $19(50.0)$ & $0.84(0.35-2.04)$ \\
\hline \multicolumn{3}{|l|}{ DRD2 (CA)n STR } \\
\hline $15 \times$ allele & $26(68.4)$ & Reference \\
\hline No $15 \times$ allele ${ }^{b}$ & $12(31.6)$ & $0.23(0.07-0.81)$ \\
\hline \multicolumn{3}{|l|}{ DRD3 MscI (Ser>Gly) } \\
\hline Ser/Ser & $24(63.2)$ & Reference \\
\hline Ser/Gly + Gly/Gly & $14(36.8)$ & $0.79(0.31-1.98)$ \\
\hline \multicolumn{3}{|c|}{ DRD3 MspI (A>G) (absence > presence of restriction site) } \\
\hline $\mathrm{A} / \mathrm{A}$ & $8(21.1)$ & Reference \\
\hline $\mathrm{A} / \mathrm{G}+\mathrm{G} / \mathrm{G}$ & $30(78.9)$ & $2.09(0.61-7.17)$ \\
\hline
\end{tabular}

${ }^{\text {a }}$ Values are given as the number $(n)$ of patients, with the percentage in parenthesis

${ }^{\mathrm{b}}$ The absence of a $15 \times \mathrm{DRD} 2 \mathrm{CA}$ repeat allele was associated with a decreased discontinuation of non-ergoline DA treatment 
The study reported here is the first to investigate determinants for the discontinuation of non-ergoline DA therapy, including pharmacogenetic determinants. Ideally, knowledge of these determinants will enable clinicians to predict an individual's response.

In conclusion, we have identified non-genetic (apomorphine use and daily levodopa dosages between 500 and $1000 \mathrm{mg}$ ) and genetic determinants [DRD2 $(\mathrm{CA})_{\mathrm{n}}$ repeat polymorphism] for the discontinuation of non-ergoline DA treatment. The DRD3 MspI polymorphism also showed a non-significant allele dose effect with non-ergoline DA treatment discontinuation, which is suggestive of a causal relationship. Confirmation of these data is warranted.

Acknowledgements We wish to thank all community pharmacists who contributed to this study.

Competing interests Jeroen van Vugt's salary is fully covered by Medisch Spectrum Twente. He has received consultancy and speaker fees from Boehringer Ingelheim, GlaxoSmithKline, Novartis Pharma, Teva Pharma and ApotheekZorg. The other authors have nothing to disclose.

Open Access This article is distributed under the terms of the Creative Commons Attribution Noncommercial License which permits any noncommercial use, distribution, and reproduction in any medium, provided the original author(s) and source are credited.

\section{References}

1. Rascol O, Brooks DJ, Korczyn AD et al (2006) Development of dyskinesias in a 5-year trial of ropinirole and L-dopa. Mov Disord 21:1844-1850
2. Arbouw ME, Movig KL, Guchelaar HJ et al (2008) Discontinuation of ropinirole and pramipexole in patients with Parkinson's disease: clinical practice versus clinical trials. Eur J Clin Pharmacol 64:1021-1026

3. Neville MJ, Johnstone EC, Walton RT (2004) Identification and characterization of ANKK1: a novel kinase gene closely linked to DRD2 on chromosome band 11q23.1. Hum Mutat 23:540545

4. Arinami T, Gao M, Hamaguchi H, Toru M (1997) A functional polymorphism in the promoter region of the dopamine D2 receptor gene is associated with schizophrenia. Hum Mol Genet 6:577-582

5. Zappia M, Annesi G, Nicoletti G et al (2005) Sex differences in clinical and genetic determinants of levodopa peak-dose dyskinesias in Parkinson disease: an exploratory study. Arch Neurol 62:601-605

6. Muglia P, Jain U, Kennedy JL (2002) A transmission disequilibrium test of the Ser9/Gly dopamine D3 receptor gene polymorphism in adult attention-deficit hyperactivity disorder. Behav Brain Res 130:91-95

7. Jeanneteau F, Funalot B, Jankovic J et al (2006) A functional variant of the dopamine $\mathrm{D} 3$ receptor is associated with risk and age-at-onset of essential tremor. Proc Natl Acad Sci USA 103:10753-10758

8. Arbouw ME, van Vugt JP, Egberts TC, Guchelaar HJ (2007) Pharmacogenetics of antiparkinsonian drug treatment: a systematic review. Pharmacogenomics 8:159-176

9. Grosset KA, Reid JL, Grosset DG (2005) Medicine-taking behavior: implications of suboptimal compliance in Parkinson's disease. Mov Disord 20:1397-1404

10. Lundstrom K, Turpin MP (1996) Proposed schizophreniarelated gene polymorphism: expression of the Ser9Gly mutant human dopamine D3 receptor with the Semliki Forest virus system. Biochem Biophys Res Commun 225:10681072

11. Wang J, Liu ZL, Chen B (2001) Association study of dopamine D2, D3 receptor gene polymorphisms with motor fluctuations in PD. Neurology 56:1757-1759 